\title{
Magnesium-induced alterations in the photosynthetic performance and resistance of rice plants infected with Bipolaris oryzae
}

\author{
Wiler Ribas Moreira ${ }^{1}$, Wilka Messner da Silva Bispo², Jonas Alberto Rios², Daniel Debona², Clístenes Williams Araújo Nascimento \\ Fabrício Ávila Rodrigues²*
}

\author{
${ }^{1}$ Federal Rural University of Pernambuco - Dept. of \\ Agronomy - 52171-900 - Recife, PE - Brazil. \\ ${ }^{2}$ Federal University of Viçosa - Dept. of Plant Pathology - \\ 36570-900 - Viçosa, MG - Brazil. \\ *Corresponding author <fabricio@ufv.br>
}

Edited by: Luís Eduardo Aranha Camargo

Received September 10, 2014

Accepted March 07, 2015

\begin{abstract}
Brown spot (BS), caused by the fungus Bipolaris oryzae, is one of the most important diseases contracted by rice. We investigated the effect of magnesium (Mg) on the development of BS, caused by Bipolaris oryzae, and the effects of disease development on the photosynthetic performance of rice (Oryza sativa L.) plants (cv. Metica-1) grown in nutrient solutions containing 0.25 or $4.0 \mathrm{mM}$ of Mg. Assessments of BS severity, leaf $\mathrm{Mg}$ and pigment concentrations (total chlorophylls and carotenoids), were carried out at $120 \mathrm{~h}$ after inoculation, in addition to gas exchange parameters,. Higher leaf concentration of $\mathrm{Mg}$ was observed in plants supplied with $4.0 \mathrm{mM} \mathrm{Mg}$ than in those supplied with $0.25 \mathrm{mM}$. The increase in leaf $\mathrm{Mg}$ was accompanied by a decrease in BS severity, higher concentration of total chlorophyll and better photosynthetic performance. Plants supplied with $4.0 \mathrm{mM} \mathrm{Mg}$ had higher average values for carbon assimilation, stomatal conductance and internal leaf $\mathrm{CO}_{2}$ concentration when compared with plants supplied with $0.25 \mathrm{mM} \mathrm{Mg}$. Conversely, the concentration of carotenoids was lower in plants supplied with the higher Mg rate. These results suggest that Mg suppresses disease severity and preserves photosynthetic performance by allowing for better stomatal conductance and, consequently, greater availability of $\mathrm{CO}_{2}$ at the carboxylation sites.

Keywords: Oryza sativa, foliar disease, macronutrient, photosynthesis, plant nutrition
\end{abstract}

\section{Introduction}

Brown spot (BS), caused by the fungus Bipolaris oryzae (Breda de Haan) Shoemaker, is one of the most important diseases that affects rice (Oryza sativa L.) (Ou, 1985) and is responsible for much of the yield loss and decrease in grain quality in the world's rice producing areas (Kohls et al., 1987). Although often unrecognized as such, mineral nutrition has always been considered a major component in the control of plant diseases and manipulation of nutrient availability by modifying the soil environment and is certainly an integral component of agricultural production (Huber and Jones, 2013; Spann and Schumann, 2010). Prabhu et al. (2012), Silva et al. (2012) and Zanão-Júnior et al. (2009) have extolled the importance of nutrient supply in the enhancement of resistance against BS severity that particularly emphasizes the role of silicon in disease attenuation. Little information, however, is available about the effect of other mineral elements which mitigate the severity of BS.

Magnesium $(\mathrm{Mg})$ is one of the most abundant free divalent cations in the cytosol of plants that has multiple functions in plant physiology (Li et al., 2001). This makes it an interesting target for investigation, since nutrients affect disease susceptibility through metabolic changes in plants (Spann and Schumann, 2010). Despite the recognized importance of $\mathrm{Mg}$ in plant metabolism, e.g. as the central atom of the chlorophyll molecule and an element required for the aggregation of ribosomes (Wilkinson et al., 1990), little information is available about the effect of this macronutrient in terms of resistance or susceptibility of plants to diseases. $\mathrm{Mg}$ is a for- gotten element in crop production (Cakmak and Yazici, 2010), and there is less documentation of the interaction between diseases and the $\mathrm{Mg}$ supply than for any other nutrient (Huber and Jones, 2013).

Across the range of studies involving the mitigation of diseases through the use of agricultural practices with nutrition, there are reports of a nonspecific role for $\mathrm{Mg}$, since its influence may either reduce or enhance the severity of disease. Jones and Huber (2007) reported 22 diseases where severity was decreased by supplying additional $\mathrm{Mg}$, 17 where it was increased and 6 that showed a variable effect, depending on the environment. However, few studies relate the effects of $\mathrm{Mg}$ also to the physiological traits of the host species.

Given the importance of $\mathrm{Mg}$ in plant nutrition and the differential evolution of disease symptoms observed in plants exposed to $\mathrm{Mg}$ in other pathosystems, the objective of the authors in the present study was to investigate the effects of $\mathrm{Mg}$ on BS development relative to the associated alterations in the photosynthetic performance in rice. It was hypothesized that $\mathrm{Mg}$ could influence the physiology of rice plants through $B$. oryzae, and thus enhance the production of substrates available to the production of defense compounds, which favor the mitigation of disease development.

\section{Materials and Methods}

\section{Plant material}

Rice plants (cv. Metica-1) were grown in Hoagland and Arnon (1950) in a modified nutrient solution consisting of: $1.0 \mathrm{mM} \mathrm{KNO}_{3}, 0.25 \mathrm{mM} \mathrm{NH}_{4} \mathrm{H}_{2} \mathrm{PO}_{4}, 0.1 \mathrm{mM}$ 
$\mathrm{NH}_{4} \mathrm{Cl}, 1.0 \mathrm{mM} \mathrm{Ca}\left(\mathrm{NO}_{3}\right)_{2}, 0.30 \mu \mathrm{M} \mathrm{CuSO}{ }_{4} .5 \mathrm{H}_{2} \mathrm{O}, 0.33$ $\mu \mathrm{M} \mathrm{ZnSO}{ }_{4} .7 \mathrm{H}_{2} \mathrm{O}, 11.5 \mu \mathrm{M} \mathrm{H}_{3} \mathrm{BO}_{3}, 3.5 \mu \mathrm{M} \mathrm{MnCl}_{2} \cdot 4 \mathrm{H}_{2} \mathrm{O}$, $0.1 \mu \mathrm{M}\left(\mathrm{NH}_{4}\right)_{6} \mathrm{Mo}_{7} \mathrm{O}_{24} \cdot 4 \mathrm{H}_{2} \mathrm{O}, 25 \mu \mathrm{M} \mathrm{FeSO} \cdot 7 \mathrm{H}_{2} \mathrm{O}$ and 25 $\mu \mathrm{M}$ ethylenediaminetetraacetic acid. Magnesium sulphate $\left(\mathrm{MgSO}_{4} \cdot 7 \mathrm{H}_{2} \mathrm{O}\right)$ was supplied as the magnesium source at either 0.25 or $4.0 \mathrm{mM}$. The magnesium rates had been established in previous experiments and were chosen according to their effects on disease development.

Sodium sulphate $\left(\mathrm{Na}_{2} \mathrm{SO}_{4}\right)$ was used at $0.25 \mathrm{mM}$ to balance the nutrient solution containing $0.25 \mathrm{mM}$ of $\mathrm{Mg}$. Also, $3.5 \mathrm{mM}$ of $\mathrm{MgCl}_{2}$ and $0.5 \mathrm{mM}$ of $\mathrm{MgSO}_{4} .7 \mathrm{H}_{2} \mathrm{O}$ were used to make $4.0 \mathrm{mM} \mathrm{Mg}$. Rice seeds were washed in sodium hypochlorite solution (10\%) for $1.5 \mathrm{~min}$ and then washed in deionized water for $3 \mathrm{~min}$. The seeds were germinated in rolls of filter paper $(15 \times 15 \mathrm{~cm})$ soaked with water and kept at $25^{\circ} \mathrm{C}$. Six seedlings were transferred to each plastic pot $(40 \times 25 \times 8 \mathrm{~cm})$ containing $5 \mathrm{~L}$ of nutrient solution with the different $\mathrm{Mg}$ levels. The nutrient solution was replaced every four days or when the electrical conductivity was $85 \%$ of the initial value. The $\mathrm{pH}$ of the nutrient solution was checked daily and maintained between 5.5 and 6.0 by the addition of $1 \mathrm{M} \mathrm{HCl}$ or $\mathrm{NaOH}$.

\section{Inoculation procedure}

The isolate of B. oryzae (UFV-DFP Bo12) was preserved on strips of filter paper placed in glass tubes containing silica gel and stored in a refrigerator at $4{ }^{\circ} \mathrm{C}$. Fifteen days before inoculation, several filter paper strips containing hyphae of $B$. oryzae, were placed in potato dextrose agar (PDA) on Petri dishes. When the mycelium of the fungus reached $3 \mathrm{~cm}$ in diameter, it was transferred to new PDA plates and maintained for ten days in a growth chamber at $25^{\circ} \mathrm{C}$ and $12 \mathrm{~h}$ photoperiod. To obtain a conidial suspension, $10 \mathrm{~mL}$ of sterilized water was added to Petri dishes containing fungal conidia, mixed using a Drigalski handle and then filtered through cotton gauze $(15 \times 15 \mathrm{~cm})$ to remove mycelia. The suspension was adjusted to $1 \times 10^{4}$ conidia $\mathrm{mL}^{-1}$ using a hemocytometer.

Gelatin was added to the suspension $(1 \% \mathrm{w} / \mathrm{v})$ to increase the adhesion of conidia to the leaf surface. Plants (30 days old, vegetative growth stage) were inoculated with the conidial suspension of $B$. oryzae until runoff using a VL Airbrush atomizer. Immediately after inoculation, plants were transferred to a mist chamber $\left(25 \pm 2{ }^{\circ} \mathrm{C}\right.$ and relative humidity of $\left.80 \pm 5 \%\right)$ for a 24 $\mathrm{h}$ dark period. Afterwards, plants were transferred to a moist chamber in a greenhouse.

\section{Disease assessment}

The fifth and sixth leaves from the main culm of each plant were marked and used to assess BS severity at 48,72, 96 and $120 \mathrm{~h}$ after inoculation (hai) using the scale proposed by the International Rice Research Institute (IRRI, 1996). Data re disease severity was used to calculate the area under the BS progress curve (AUB-
SPC) according to the formula proposed by Shaner and Finney (1977).

\section{Determination of leaf $\mathrm{Mg}$ concentration}

Leaf samples collected from the main culm of each plant were washed in distilled water, dried in an oven with forced ventilation $\left(70^{\circ} \mathrm{C}\right)$ until constant weight and ground in a Thomas-Wiley mill type to pass through a 20 mesh sieve. The foliar Mg concentration before fungal inoculation was determined by nitropercloric digestion of $0.5 \mathrm{~g}$ of leaf sample in $10 \mathrm{~mL}$ of $\mathrm{HNO}_{3}$ at $200{ }^{\circ} \mathrm{C}$ (Bataglia et al., 1983) in order to evaluate the effect of this macronutrient on BS development.

\section{Determination of photosynthetic pigments}

Leaf samples from the fourth leaf of the main culm of non-inoculated and inoculated plants $(48,72$, 93 and 120 hai) were collected and stored at $-80^{\circ} \mathrm{C}$ until analyzed. A total of $200 \mathrm{mg}$ of leaf tissue was ground in liquid nitrogen with $0.1 \mathrm{~g}$ of calcium carbonate and then homogenized with $2 \mathrm{~mL}$ of $80 \%$ acetone (v/v) under green light. The resulting suspension was filtered through Whatman filter paper \# 1 . The residue was washed three times in $80 \%$ acetone and the final volume was brought to $25 \mathrm{~mL}$ with the same solvent. Absorbance of the extracts was read in a spectrophotometer at $470,646.8$ and $663.2 \mathrm{~nm}$ wavelengths. The concentrations of total chlorophyll $(a+b)$ and carotenoids were estimated according to Lichtenthaler (1987).

\section{Leaf gas exchange measurements}

The net carbon assimilation rate $(A)$, stomatal conductance to water vapor $\left(g_{\mathrm{s}}\right)$ and internal $\mathrm{CO}_{2}$ concentration $\left(C_{\mathrm{i}}\right)$ were measured on the fourth leaf from the main culm of each non-inoculated and inoculated plant at 48 , 72,96 and 120 hai using a portable open-flow gas exchange system (LI-6400XT). Measurements were made from $9 \mathrm{~h} 00$ to $12 \mathrm{~h} 00$ under an artificial photosynthetic photon flux density of $1200 \mu \mathrm{mol}$ photons $\mathrm{m}^{-2} \mathrm{~s}^{-1}$ and $\mathrm{CO}_{2}$ concentration of $400 \mu \mathrm{mol} \mathrm{mol}{ }^{-1}$. Intrinsic water use efficiency was calculated by using the ratio between the $A$ and $g_{\text {s }}$ values.

\section{Experimental design and statistics}

A $2 \times 2$ factorial experiment, consisting of two $\mathrm{Mg}$ rates $(0.25$ and $4.0 \mathrm{mM})$ and non-inoculated or inoculated plants, was arranged in a completely randomized design with four replications per treatment at each sampling time. The experiment was repeated once. Data were analyzed for variance and the treatment means from noninoculated and inoculated plants at each $\mathrm{Mg}$ rate (as well as between $\mathrm{Mg}$ rates for non-inoculated and inoculated plants), at each sampling time, and were compared by Student's $t$ test $(p \leq 0.05)$ using SAS (Release 8.02 Level 02M0 for Windows, SAS (Statistical Analysis System, 1989). Correlation analysis was carried out to evaluate the relationships between AUBSPC, Mg leaf tissue concentration and parameters $A, g_{\mathrm{s}^{\prime}} C_{\mathrm{i}}$ and $A / g_{\mathrm{s}}$ for inoculated plants. 


\section{Results}

Disease assessment: The AUBSPC declined (by $25 \%$ ) as the $\mathrm{Mg}$ rate increased from 0.25 to $4.0 \mathrm{mM}$ (613.8 and 460.8 , respectively).

Leaf Mg concentration: Leaf Mg increased (on average

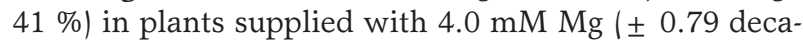
gram per kilogram, dag $\mathrm{kg}^{-1}$ ) when compared to those supplied with $0.25 \mathrm{mM}\left( \pm 0.47 \mathrm{dag} \mathrm{kg}^{-1}\right)$.

Photosynthetic pigments: Total chlorophyll was higher (on average $20 \%$ ) in plants supplied with $4.0 \mathrm{mM}$ $\mathrm{Mg}$ when compared to those with $0.25 \mathrm{mM}$ (Figure 1A), regardless of the inoculation treatment (Figure 1B). The carotenoid concentration in inoculated plants declined by $25 \%$ (on average) as the $\mathrm{Mg}$ rate increased from 0.25 to $4.0 \mathrm{mM}$ (Figure $1 \mathrm{~B}$ ).

Leaf gas exchange measurements: $A, g_{s}$ and $A / g_{s}$ values were higher for non-inoculated plants when com-

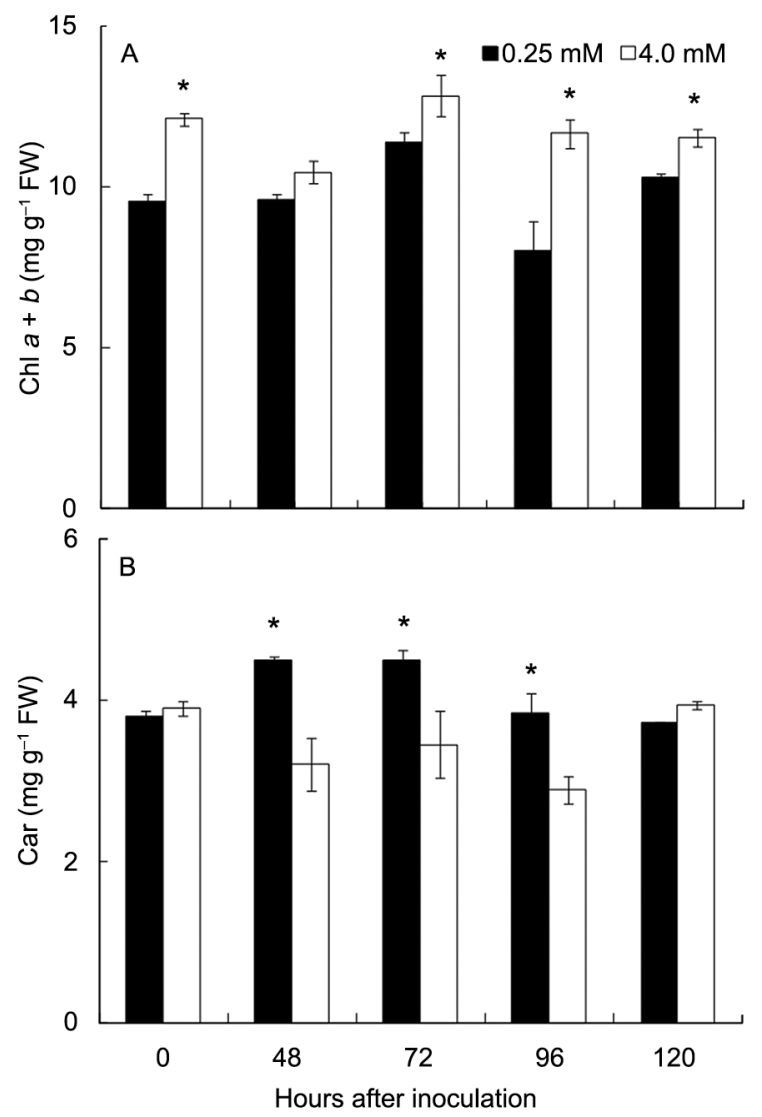

Figure 1 - Concentrations of total chlorophyll $(\mathrm{Chl} a+b)(A)$ and carotenoids (Car) (B) in leaves of rice plants grown with 0.25 and $4.0 \mathrm{mM} \mathrm{Mg}$ and inoculated with Bipolaris oryzae. Means followed by an asterisk ( ${ }^{*}$ ) are different between the two Mg supplies at each evaluation time (Student's $t$ test, $p \leq 0.05$ ). Error bars represent the standard error of the mean. $n=4$. FW $=$ fresh weight. pared with inoculated plants during the evaluation times, regardless of the $\mathrm{Mg}$ rates (Figure 2). For non-inoculated plants supplied with $0.25 \mathrm{mM} \mathrm{Mg}, A, g_{\mathrm{s}}$ and $C_{\mathrm{i}}$ were 54 , 75 and $12 \%$ higher respectively, (on average) when compared with inoculated plants. At the rate of $4.0 \mathrm{mM} \mathrm{Mg}$, $A, g_{\mathrm{s}}$ and $C_{\mathrm{i}}$ were, 39,50 and $5 \%$ higher, respectively, (in average) for the non-inoculated plants in comparison to the inoculated ones. The values for $A / g_{s}$ were 46 and 17 $\%$ higher (on average) in inoculated plants at the two $\mathrm{Mg}$ rates when compared with non-inoculated plants (Figure $2 \mathrm{H})$. Values for $A, g_{\mathrm{s}}$ and $C_{\mathrm{i}}$ of non-inoculated plants supplied with $0.25 \mathrm{mM} \mathrm{Mg}$ were 13, 35 and $6 \%$ higher, respectively, and the $A / g_{s}$ value was $29 \%$ lower compared with plants supplied with $4.0 \mathrm{mM} \mathrm{Mg}$. Inoculated plants supplied with $4.0 \mathrm{mM} \mathrm{Mg}$ had higher $A, g_{\mathrm{s}}$ and $C_{\mathrm{i}}$ (an average of 20,31 and $6 \%$, respectively) and lower $A / g_{\mathrm{s}}$ (an average of $28 \%$ ) when compared with plants supplied with $0.25 \mathrm{mM} \mathrm{Mg}$ (Figure 2).

Correlation analysis: The correlation between AUBSPC and leaf $\mathrm{Mg}$ concentration $(\mathrm{r}=-0.91$ and -0.46 , respectively, for the lower and higher $\mathrm{Mg}$ rate) was negative (Table 1). There were also positive correlations of leaf $\mathrm{Mg}$ concentration with the majority of the gas exchange parameters. AUBSPC had negative correlation with $A, g_{\mathrm{s}^{\prime}} C_{\mathrm{i}}$ and $A / g_{\mathrm{s}}$ (Table 1 ).

\section{Discussion}

Rice plants supplied with the highest $\mathrm{Mg}$ rate contained more foliar Mg which contributed to reducing the AUBSPC. Negative correlations of foliar Mg with disease severity (especially the effect of the lower $\mathrm{Mg}$ rate on symptoms development) found in the present study are consistent with previous studies in terms of the response of plants to $\mathrm{Mg}$ soil amendment for BS control.

Moreira et al. (2013) reported that a higher foliar concentration of $\mathrm{Mg}$ indirectly increased rice resistance to infection by $B$. oryzae mainly through modulating the activity of defense enzymes. When corroborating the reported potential and empirical effects of $\mathrm{Mg}$ in reducing BS severity, we also found that there was a pronounced decrease in gas exchange parameters (especially $A$ and $\left.g_{s}\right)$ in inoculated plants regardless of the $\mathrm{Mg}$ rate. This fact, along with the negative correlations between disease severity and gas exchange parameters substantially supports the negative effects of BS on rice physiology as already reported by Dallagnol et al. (2011).

Fungal colonization of rice leaf tissues diminished $g_{s}$ over time compared with non-inoculated plants. This reduction may be initially related somehow to fungal ingress into host tissues, where the mycelium formed by germinated conidia may penetrate directly into epidermal cells as well as through stomata (Tullis, 1935). Stomatal closure is a primary innate immunity response to pathogen-associated molecular patterns (PAMPs) for bacterial and fungal pathogens (Melotto et al., 2006; Gudesblat et al., 2009). Furthermore, being a necrotro- 



Hours after inoculation

Figure 2 - Net carbon assimilation rate $(A)(A$ and $B)$, stomatal conductance to water vapor $\left(g_{s}\right)(C$ and $D)$, internal $\mathrm{CO}_{2}$ concentration $\left(C_{i}\right)(E$ and $F)$ and intrinsic water use efficiency $\left(A / g_{s}\right)(G$ and $H)$ of leaves of rice plants non-inoculated $(N I)(A, C, E$ and $G)$ and inoculated $(I)(B, D, F$ and $H)$ with Bipolaris oryzae and with 0.25 and $4.0 \mathrm{mM} \mathrm{Mg}$. Means followed by an asterisk ( ${ }^{*}$ ) are different between the two Mg supplies at each evaluation time (Student's $t$ test, $p \leq 0.05$ ). Means followed by the symbols $\boldsymbol{\Delta}$ and $\boldsymbol{\nabla}$, respectively, show differences between $\mathrm{NI}$ and I plants for the higher and lower Mg supplies at each evaluation time (Student's $t$ test, $p \leq 0.05$ ). Error bars represent the standard error of the mean. $n=4$.

phic pathogen, non-host selective toxins (ophiobolins A and $\mathrm{B}$ ) produced by $B$. oryzae may cause tissue necrosis to damage the leaf blade structure and also favor a reduction in $g_{s}$ (Tullis, 1935; Dallagnol et al., 2011). Subsequent limitation in diffusion may have reduced the $\mathrm{CO}_{2}$ uptake from the atmosphere, reducing $C_{\mathrm{i}}$ as a consequence. Thus, as fungal infection takes place, carbon dioxide diffusion through the mesophyll may be constrained, hindering the carbon arrival at carboxylation sites and impairing photosynthesis.

The changes observed in the regulation of guard cells and the physical disruption of the cuticle and stomata negatively affect the regulation of plant water relationships. The regulation of stomata opening and closure has 
Table 1 - Pearson correlation coefficients for net carbon assimilation rate $(A)$, stomatal conductance to water vapor $\left(g_{s}\right)$, internal $\mathrm{CO}_{2}$ concentration $\left(C_{i}\right)$, intrinsic water use efficiency $\left(A / g_{s}\right)$, area under the brown spot progress curve (AUBSPC) and leaf Mg concentration of plants supplied with 0.25 and $4 \mathrm{mM} \mathrm{Mg}$.

\begin{tabular}{lcccccc}
\hline Parameters & $\mathrm{A}$ & $g_{\mathrm{s}}$ & $C_{\mathrm{i}}$ & $\mathrm{A} / g_{\mathrm{s}}$ & $\mathrm{AUBSPC}$ & $\mathrm{Mg}$ \\
\hline $\mathrm{A}$ & - & $0.98^{*}$ & $0.84^{*}$ & $0.74^{*}$ & $-0.94^{*}$ & $0.69^{*}$ \\
$g_{\mathrm{s}}$ & $0.92^{*}$ & - & $0.82^{*}$ & $0.85^{*}$ & $-0.97^{*}$ & $0.64^{*}$ \\
$\mathrm{C}_{\mathrm{i}}$ & $0.76^{*}$ & $0.94^{*}$ & - & $0.52^{*}$ & $-0.90^{*}$ & 0.21 \\
$\mathrm{~A} / \mathrm{g}_{\mathrm{s}}$ & $0.93^{*}$ & $0.76^{*}$ & $0.76^{*}$ & - & $-0.83^{*}$ & $0.51^{*}$ \\
$\mathrm{Sev}$ & -0.29 & $-0.64^{*}$ & $-0.75^{*}$ & $-0.52^{*}$ & - & $-0.46^{*}$ \\
$\mathrm{Mg}$ & $0.56^{*}$ & $0.84^{*}$ & $0.95^{*}$ & $0.65^{*}$ & $-0.91^{*}$ & - \\
\hline
\end{tabular}

The values below and above the diagonal are Pearson's $r$ coefficient for the lower $(0.25 \mathrm{mM})$ and the higher $(4.0 \mathrm{mM}) \mathrm{Mg}$ rates, respectively. The symbol * indicates differences (Student's $t$ test, $p<0.01$ ).

great importance in the avoidance of water loss (Grimmer et al., 2012). The lower stomatal conductance found for the inoculated plants, regardless of the $\mathrm{Mg}$ rate, may have reduced the diffusion of water from plant to atmosphere as reported by Condon et al. (2004) and Grimmer et al. (2012) considering that stomatal closure results in a more pronounced impact on the diffusion of water out of the stomata than on the photosynthetic rate. Indeed, the $A / g_{\text {s }}$ ratio increased in inoculated plants during the time course of the experiment independent of the $\mathrm{Mg}$ rate.

Physical and chemical responses to fungal infection require metabolic energy provided by increased respiratory rates, which depend on the availability of substrates from photosynthesis which, in turn, depend on an adequate level of foliar $\mathrm{Mg}$ (Horsfall and Cowling, 1980). The negative effects of BS on leaf structure and host physiology appear to enhance the infection process, generating a loop in which the more extensive colonization of tissues disadvantage the plant's photosynthetic performance and reduce the availability of substrates needed for the production of energy and defense compounds, leading to further tissue colonization and disease development. This way, considering inoculated plants, it can be suggested that, even with the general detrimental effects of inoculation, $\mathrm{Mg}$ supply and its coupled essential and beneficial effects on host photosynthesis may have favored and subsidized the development of defense responses thereby resulting in the reduction of disease severity on plants supplied with the highest $\mathrm{Mg}$ rate.

Magnesium also plays a fundamental role in phloem export of photosynthates, partitioning of dry matter between roots and shoots and its deficiency generally results in the accumulation of amino acids and sugars in leaves (Cakmak and Kirkby, 2008). The negative effects of the accumulation of sugars on photosynthesis and general carbon metabolism have been previously reported (Stitt et al., 1990; Wingler et al., 2000). In fact, in addition to the observed reductions in $A$, inoculated plants supplied with $0.25 \mathrm{mM} \mathrm{Mg}$ also reduced root growth compared to those supplied with $4.0 \mathrm{mM} \mathrm{Mg}$ (data not shown), corroborating the role of $\mathrm{Mg}$ in carbon partitioning.

The development of necrotic lesions and the consequent reduction in healthy green leaf area may also have contributed to reduced light capture and energy achievement. Magnesium plays a critical role in capturing solar energy and releasing it to the photochemical process of photosynthesis, given that up to one fifth of the magnesium structural pool is involved in the chlorophyll structure (Mengel and Kirkby, 1987; Wilkinson et al., 1990). Therefore, the higher chlorophyll concentration observed for both inoculated and non-inoculated plants supplied with $4.0 \mathrm{mM} \mathrm{Mg}$ may be a direct result of increased availability of this macronutrient for synthesizing these pigments. In sharp contrast, inoculated plants supplied with the lowest $\mathrm{Mg}$ rate had higher carotenoid concentration, indicative of the greater disease severity of these plants.

Carotenoids act as accessory pigments and may be involved in the protection of the chloroplastidic membrane by scavenging singlet oxygen and quenching the triplet state of chlorophyll (Demmig-Adams, 1990; Candan and Tarhan, 2003; Takano et al., 2005). Increased antioxidant activity in rice plants inoculated with $B$. oryzae has already been reported (Dallagnol et al., 2011; Hermans and Verbruggen, 2005). Cakmak and Kirkby (2008) reported chlorophyll breakdown and the generation of highly reactive oxygen species in plants under $\mathrm{Mg}$ deprivation.

Magnesium is considered an essential mineral element for plants and, as a component of the abiotic environment, its availability has a profound effect on biological activity, strikingly influencing plant growth and vigor (Weinberg, 1977; Huber and Jones, 2013). Based on these assumptions, we conclude that healthy leaf area (suitable for photosynthesis) is negatively impaired during infection by $B$. oryzae and that the $\mathrm{Mg}$ supply contributed to the maintenance of more efficient light capture and photosynthetic performance. These improvements potentially favored the enhancement of substrate production for mounting defenses against disease advance.

\section{Acknowledgements}

F.A.R. and C.W.A. Nascimento thank the Brazilian National Council for Scientific and Technological Development (CNPq) for their fellowship. This study was supported by grants from Coordination for the Improvement of Higher Level Personnel (CAPES), CNPq, 
the Minas Gerais State Foundation for Research Support (FAPEMIG) and the Foundation for Science and Technology of the State of Pernambuco (FACEPE).

\section{References}

Bataglia, O.C.; Furlani, A.M.C.; Teixeira, J.P.F. 1983. Methods of Chemical Analysis of Plants = Métodos de Análise Química de Plantas. Instituto Agronômico de Campinas, Campinas, SP, Brazil. (Boletim Técnico, 78) (in Portuguese).

Cakmak, I.; Kirkby, E.A. 2008. Role of magnesium in carbon partitioning and alleviating photo-oxidative damage. Physiological Plantarum 133: 692-704.

Cakmak, I.; Yazici, A.M. 2010. Magnesium: a forgotten element in crop production. Better Crops 94: 23-25.

Candan, N.; Tarhan, L. 2003. Changes in chlorophyll-carotenoid contents, antioxidant enzyme activities and lipid peroxidation levels in Zn-stressed Mentha pulegium. Turkish Journal of Chemistry 27: 21-30.

Condon, A.G.; Richards, R.A.; Rebetzke, G.J.; Farquhar, G.D. 2004. Breeding for high water-use efficiency. Journal of Experimental Botany 55: 2447-2460.

Dallagnol, L.J.; Rodrigues, F.A.; Martins, S.C.V.; Cavatte, P.C.; DaMatta, F.M. 2011. Alterations on rice leaf physiology during infection by Bipolaris oryzae. Australasian Plant Pathology 40: 360-365.

Demmig-Adams, B. 1990. Carotenoids and photoprotection: a role for the xanthophyll zeaxanthin. Biochimica et Biophysica Acta 1020: $1-24$.

Grimmer, M.K.; Foulkes, M.J.; Paveley, N.D. 2012. Foliar pathogenesis and plant water relations: a review. Journal of Experimental Botany 63: 4321-4331.

Gudesblat, G.E.; Torres, P.S.; Vojnov, A.A. 2009. Xanthomonas campestris overcomes Arabidopsis stomatal innate immunity through a DSF cell-to-cell signal-regulated virulence factor. Plant Physiology 149: 1017-1027.

Hermans, C.; Verbruggen, N. 2005. Physiological characterization of Mg deficiency I Arabidopsis thaliana. Journal of Experimental Botany 56: 2153-2161.

Hoagland, D.R.; Arnon, D.I. 1950. The Water Culture Method for Growing Plant without Soil. California Agricultural Experiment Station, Davis, CA, USA. (Circular, 347).

Horsfall, J.G.; Cowling, E.B. 1980. Plant Disease: An Advanced Treatise; How Plants Defend Themselves. Academic Press, New York, NY, USA.

Huber, D.M.; Jones, J.B. 2013. The role of magnesium in plant disease. Plant Soil 368: 73-85.

International Rice Research Institute [IRRI]. 1996. Standard Evaluation System for Rice. IRRI, Los Banos, Philippines.

Jones, J.B.; Huber, D.M. 2007. Magnesium and plant disease. In: Datnoff, L.E.; Elmer, W.H.; Huber, D.M., eds. Mineral nutrition and plant disease. APS Press, St. Paul, MN, USA.

Kohls, C.L.; Percich, J.A.; Huot, C.M. 1987. Wild-rice yield losses associated with growth-stage-specific fungal brown spot epidemics. Plant Disease 71: 419-422.

Li, L.; Tutone, A.F.; Drummond, R.S.; Gardner, R.C.; Luan, S. 2001. A novel family of magnesium transport genes in Arabidopsis. The Plant Cell 13: 2761-2775.
Lichtenthaler, H.K. 1987. Chlorophylls and carotenoids, the pigments of photosynthetic biomembranes. p. 350-382. In: Douce, R.; Packer, L., eds. Methods in enzymology, Academic Press, New York, NY, USA.

Melotto, M.; Underwood, W.; Koczan, J.; Nomura, K.; He, S.Y. 2006. Plant stomata function in innate immunity against bacterial invasion. Cell 126: 969-980.

Mengel, K.; Kirkby, E.A. 1987. Principles of Plant Nutrition. International Potash Institute, Bern, Switzerland.

Moreira, W.R.; Resende, R.S.; Rodrigues, F.A.; Andrade, C.C.L.; Nascimento, C.W.A. 2013. Magnesium on rice resistance to brown spot. Bragantia 72: 154-161 (in Portuguese, with abstract in English).

Ou, S.H. 1985. Rice Diseases. 2ed. Commonwealth Mycological Institute, Kew, England.

Prabhu, A.S.; Barbosa Filho, M.P.; Datnoff, L.E.; Snyder, G.H.; Berni, R.F.; Rodrigues, F.A.; Dallagnol, L.J. 2012. Silicon reduces brown spot severity and grain discoloration on several rice genotypes. Tropical Plant Pathology 37: 409-414.

Shaner, G.; Finney, R.E. 1977. The effect of nitrogen fertilization on the expression of slow-mildewing resistance in Knox wheat. Phytopathology 67: 1051-1056.

Silva, M.R.J.; Pereira, S.C.; Rodrigues, F.A.; Zanão Júnior, L.A.; Fontes, R.L.F.; Oliveira, M.G.A. 2012. Silicon and manganese on the activity of enzymes involved in rice resistance against brown spot. Tropical Plant Pathology 37: 339-345.

Spann, T.M.; Schumann, A.W. 2010. Mineral nutrition contributes to plant disease and pest resistance. Available at: http://edis. ifas.ufl.edu [Accessed Dec, 2013].

Stitt, M.; Schaewen, A. von; Willmitzer, L. 1990. "Sink" regulation of photosynthetic metabolism in transgenic tobacco plants expressing yeast invertase in their cell wall involves a decrease of the Calvin-cycle enzymes andan increase of glycolytic enzymes. Planta 183: 40-50.

Takano, M.; Xie, X.; Inagaki, N.; Shinomura, T. 2005. Distinct functions of phytochromes on the photomorphogenesis in rice. p. 111-117. In: Wada, M.; Shimazaki, K.; Iino, M., eds. Light sensing in plants. Springer-Verlag, Tokyo, Japan.

Tullis, E.C. 1935. Histological studies of rice leaves infected with Helminthosporium oryzae. Journal of Agricultural Research 50: 82-90.

Weinberg, E.D. 1977. Micro-organisms and Minerals. Marcel Dekker, New York, NY, USA.

Wilkinson, S.R.; Welch, R.M.; Mayland, M.F.; Grunes, D.L. 1990. Magnesium in plants: uptake, distribution, function, and utilization by man and animals. p. 33-56. In: Sigel, H.; Sigel, A., eds. Metal ions in biological systems: compendium on magnesium and its role in biology, nutrition, and physiology. Marcel Dekker, New York, NY, USA.

Wingler, A.; Lea, P.J.; Quick, W.P.; Leegood, R.C. 2000. Photorespiration: metabolic pathways and their role in stress protection. Philosophical Transactions of the Royal Society B 355: 1517-1529.

Zanão Júnior, L.A.; Rodrigues, F.A.; Fontes, R.L.F.; Korndörfer, G.H.; Neves, J.C.L. 2009. Rice resistance to brown spot mediated by silicon and its interaction with manganese. Journal of Phytopathology 157: 73-78. 